\title{
A Review of Reductionist versus Systems Perspectives towards 'Doing the Right Strategies Right' for Circular Economy Implementation
}

\author{
Raquel Balanay ${ }^{1}$ and Anthony Halog ${ }^{2, *(\mathbb{D})}$ \\ 1 College of Agriculture and Agri-industries, Caraga State University, Ampayon, Butuan City 8600, Philippines; \\ raquelbalanay@gmail.com \\ 2 School of Earth and Environmental Sciences, The University of Queensland, Brisbane, QLD 4072, Australia \\ * Correspondence: a.halog@uq.edu.au
}

Citation: Balanay, R.; Halog, A. A

Review of Reductionist versus

Systems Perspectives towards 'Doing the Right Strategies Right' for Circular Economy Implementation. Systems 2021, 9, 38. https://doi.org/ $10.3390 /$ systems 9020038

Academic Editor: Wayne Wakeland

Received: 11 May 2021

Accepted: 26 May 2021

Published: 31 May 2021

Publisher's Note: MDPI stays neutral with regard to jurisdictional claims in published maps and institutional affiliations.

Copyright: (c) 2021 by the authors. Licensee MDPI, Basel, Switzerland. This article is an open access article distributed under the terms and conditions of the Creative Commons Attribution (CC BY) license (https:// creativecommons.org/licenses/by/ $4.0 /)$.
Abstract: This systematic review examines the importance of a systems/holistic approach in analyzing and addressing the footprints/impacts of business-as-usual activities regarding the development of a circular economy (CE). Recent works on why current CE approaches have to be examined in terms of reductionist vs. systems perspectives are reviewed to tackle questions pertaining to the right or the wrong way of CE implementation. 'Doing the right thing right' is essential for sustainability - the ultimate goal of a CE, which must be viewed as a system to begin with. The limited reductionist approach overlooks and thus cannot prognosticate on the formidable unintended consequences that emerge from 'doing the right things wrong', consequences that become too costly to undo. The systems approach, being holistic, is complicated and difficult to pursue but open to exciting opportunities to integrate innovations in CE analysis and implementation. Complexity is an inherent downside of the systems approach. However, both approaches are complementary, as reductionist models can be combined to create a system of comprehensive analysis to correct the approach towards implementation of current CE initiatives. This review reports that advancements in systems analytical frameworks and tools are highly important for creating general guidelines on $\mathrm{CE}$ analysis and implementation.

Keywords: reductionist approach; systems thinking; circular economy; systems models; sustainability; holons; unintended outcomes; sustainable development goals; nature-based solutions

\section{Introduction}

Adherents of the circular economy (CE) have been increasing in number across the world, as the CE continues to be highly relevant regarding global sustainability issues and in the achievement of sustainable development goals, with pragmatic solutions provoking incisive examinations into unsustainable current ways of doing things [1,2]. Research on vanguard initiatives has continuously projected the ill-effects of business-as-usual and linear methods, of which multifaceted environmental issues highly damaging to societies are a consequence [3-5]. Factors in plain sight show economies grappling with these continuing linear methods, triggering footprints with extensive impacts that induce climate change and global warming, etc. as a result of people and economies failing to live within the boundaries of the planet's resources [1,6-9]. The urgency of mitigation and adaptation now resonates in the wake of many extreme recent phenomena causing unprecedented environmental catastrophes in many parts of the globe (e.g., wildfires, floods, plastics in the ocean) [10], in spite of intensified CE initiatives and investments globally. China, the first country with a Circular Economy Promotion Law, implemented in 2009, has advanced the CE because of the environmental damages the country has accumulated over the years $[11,12]$. Other advanced countries have joined China in pursuing a global strategy to 
fulfill a well-orchestrated movement towards the attainment of sustainable development goals (SDGs) with a view to performing a great service to humanity [11,12].

Since the introduction of the circular economy, the hoped-for results and outcomes are impressive economy-wide contributions, along with the evolution of new products, supply chains, and markets [2], as recently demonstrated in individual cases reported, particularly in Australia and China $[13,14]$. Such cases have exhibited the extensive benefits of the essential functions of circular economy principles and guidelines in reducing waste and creating value along supply chains in the process. Both Australian and Chinese cases have evaluated the advantages to their economies produced by the promotion of 'circular' opportunities across their economic landscapes, along with influential policy instruments [13,14]. Bassi et al. (2020) [15] revisited various CE strategies as implemented across Europe, specifically in Maribor, Central Germany, Scotland, Brussels, Basque Country, and Sicily, noting the various cases of successful implementation and evaluating potential sources of success and impediments to CE implementation. In their work, the operational definition of sustainability/sustainable development has been exhibited through adopted circular strategies brought about by the decisions to address major environmental issues, such as waste buildup from unchanged consumption patterns, and by means of multistakeholder involvement and political will. In a similar context, the circular economy is summarized as a globally advocated strategy to attain efficiency, sustainability, and sustainable development, with verifiable actions and progress indicators, moving towards a hopefully seamless integration into modern society. This has been an ambitious goal of regions adopting CE for observable and extensive sustainability results.

The circular economy, as a promising response to sustainability issues, is a crucible for carefully designed ecofriendly actions and integrative mechanisms in enterprises, households, and societies for the attainment of the desired outcomes [14]. It is in this context that CE strategies are examined, with the use of metrics, indicators, and standards. The desired outcomes of the CE are well embedded and articulated in the sustainable development goals that the $\mathrm{UN}$ and its member countries have vowed to achieve along a designated timeline. Because of their mutual relevance, the CE and the UN SDGs are importantly associated with each other, the CE providing the general guideposts and blueprints towards the attainment of the said goals. Within this context, the CE and its implementation are approached via careful study and planning, taking into account the fact that many of the former's aspects are still vague and in need of scientific scrutiny and updating $[16,17]$. Unintended outcomes of attempts to implement the CE are not all found to be positive $[2,18]$ when calculated steps are set out in order to bring about hopefully net positive outcomes. It is important to properly frame the perspectives via which the said steps are established, which this work aims to tackle in order to provide important guidelines for the future. A systematic review of published articles on the popular perspective (reductionist) is used to compare with another perspective (systemslevel) to harmonize both in the context of CE implementation. Insights from this review can contribute to the strengthening of guidelines regarding framework development and the choice of analytical approaches and tools for CE implementation at any level.

\section{The Circular Economy and Its Emerging Issues}

As a concept, the circular economy proposes nature-based solutions and mimics Earth's system in its ability to regenerate and restore itself with the use of renewable energy resources and a wide-range of closed-loop strategies (far more than recycling) in order to contain the footprints of the various activities carried out by industries and people, as well as to reduce the pressure on natural resource stocks, despite the constancy of fluxes within the system $[2,17,19,20]$. This is an exciting concept to explore [21], when countries globally have systematically tried to get by, rather than to do nothing at all, in the hope of achieving sustainability through metabolizing the footprints and externalities from anthropogenic and/or industrial activities and processes, designing out waste, or closing loops. With closing the loops, adherents to the concept have not yet stopped increasing as 
more promotional efforts are put in place to be extensive in actions and hopefully in results, which indicates the desperation to quickly restore the past environment where people and industries were much safer ecologically. Skene [17] nonetheless argued otherwise, citing closed loops as inconsistent with the laws of nature and Earth as a system where CE is happening. However, for this part of the review, 32 research works published since 2017 were downloaded from Google Scholar with the use of keywords-circular economy issues, limits, limitations, barriers, and challenges - in the search to sort out the CE issues that need to be the subject of discussion for the succeeding parts. Out of that number, 21 works were finally selected based on relevance, particularly to the critical aspects of CE implementation to tackle $C E$ issues in both research and practice.

The CE is yet a porous concept and a work in progress, in which the bottlenecks to make CE a reality as researched are mounting at various scales, levels, and perspectives. Divergent views and perspectives are noted, particularly as to which aspects should be essentially clarified in terms of foundations, scope, sectors, categories, indicators, and metrics, among others. These have been strongly manifested in the works of Korhonen et al. [2] and Kirchherr et al. [22], although convergence of the said works is pointed out with the observations made by Kirchherr and van Santen [21] regarding the current state of CE implementation. Particularly, Kirchherr and van Santen [21] observed that the empirical works of CE implementation were yet inadequate, few, biased towards the manufacturing sector and the developed economies, and lacking expert advice. Nonetheless, adherents (adopters and practitioners) have to be continually warned of numerous tradeoffs and deficiencies in many aspects of the implementation of CE strategies, which largely need expert analysis and guidance in the hope of closing the loop successfully $[17,18,23]$. The works reviewed herein exhibit that while CE is an exciting concept [21], stakeholders across the world have a lot yet to do to prosper significantly on this ambitious endeavor. With the extremely challenging situation in CE implementation, Kirchherr and van Santen [21] warn about the business sector-a main actor of CE-starting to lose grip.

Global circularity is around $9 \%$ so far [21], causing positivists to assert that there is a need to do a lot to keep the CE endeavor going with sustained passion and determination. To this end, Korhonen et al. [2] emphasized the importance of understanding the underpinnings of the CE concept, which also extends to the need for further investigation of the six limits of CE they had put together for intelligent/systematic action/response: "thermodynamic limits, system boundary limits, limits posed by the physical scale of the economy, limits posed by path dependency and lock-in, limits of governance and management, and limits of social and cultural definitions." The said limits may not have captured the strong interests of CE researchers at this point, but as seen in Table 1, the willingness to embark upon serious studies on the limiting outcomes of CE implementation initiatives is undeniably increasing. Research on the barriers and issues of CE implementation is rationalized with the interest of finding the ways of overcoming the overlooked and unexplored potential impediments to implementation. The limits are the credible explanations of the current observation about CE implementation in which progress is slowed down by the presence of those impediments, which make the CE only move forward in circles. Table 1 contains these impediments that slow down the efforts to fulfill circularity and put the current CE passion and initiatives onto a dilemmatic course. These impediments have created a tremendous challenge for all $\mathrm{CE}$ advocates, stakeholders, and practitioners to review their $\mathrm{CE}$ research and practice paradigms and frameworks for the necessary changes to get close to the highly ambitious goal of debunking the impossibility of full circularity for sustainability. 
Table 1. The major issues of circular economy implementation.

\begin{tabular}{lc}
\hline \multicolumn{1}{c}{ Scope and Particulars } & Sources \\
\hline $\begin{array}{l}\text { Lack of essential information and knowledge (e.g., environmental } \\
\text { impacts, CE concept, critical players, efficient strategies, }\end{array}$ & {$[1,22,24-32]$} \\
mechanisms, and implementation methods) & \\
Lack of technology, infrastructural, and logistic support & {$[1,22,25-31,33-35]$} \\
Lack of collaborative innovation & {$[25,27-29,33,36]$} \\
Uncertain profitability, costliness of the accompanying endeavors, & \\
limited funding support, financial risk, and time mismatch in cost & {$[22,24-30,33,35,36]$} \\
and benefit generation & \\
Lack of incentives and enabling sustainability & {$[22,25,26,28-31,33-35,37]$} \\
legislation/policy/guidelines & {$[1,25-29,35]$} \\
Lack of appropriate standards, metrics, and indicators & {$[27,37]$} \\
Lack of coherence in directions, contexts, and strategies & {$[24,25,28,30]$} \\
$\begin{array}{l}\text { Operational risks and lack of expertise } \\
\text { Lack of consumer interest }\end{array}$ & {$[22,25,26,28-30,35,36]$} \\
$\begin{array}{l}\text { Unwanted ecological, economic, and social changes and effects } \\
\text { (e.g., emissions, cannibalization, product complexity, externalities } \\
\text { preventing companies from exploiting refurbished products, }\end{array}$ & {$[2,23,25,26,31,38]$} \\
price effects, brand image, and fashion change) & \\
Lack of understanding, interest, and enthusiasm among key & {$[1,22,26,28,30,35]$} \\
stakeholders & {$[37]$} \\
Failure to align with market particularities & {$[29]$} \\
Limited economic feasibility of scaled-up infrastructure and & \\
technologies & \\
\hline
\end{tabular}

\section{Reductionism vs. Holism in Circular Economy: Relevance and Limits}

The impediments/issues to circular economy implementation in Table 1 comprise the difficult challenge to the current CE research methodologies, which entail looking into as many aspects as possible at both micro and macro levels for potential impacts, besides the $\mathrm{CE}$ feasibility concerns and sustainability challenges posed by Skene [17] and Korhonen et al. [2]. They convey the overlooked areas or aspects of the CE that have been tried to be implemented down to the grassroots. The traction of the $\mathrm{CE}$ on the ground definitely depends on overcoming these issues that have to be accounted for as a disruption stirring over the space where the CE is intended to take root [17]. While research helps greatly in speculating about the outcomes of the said disruption, research frameworks and methodologies have yet to be sorted out to address these limiting concerns as much as possible. Over the spectrum of research, two lines of thought direct the process with which the scientific inquiry is generally carried out: reductionist and systems. Reductionist paradigms in R\&D are not at all bad. In fact, it is with the use of its narrowing processes that many discoveries have been made of great help to individuals, groups, and societies (e.g., the framing of the international development goals) [18,39]. In research, reductionism works with sufficient simplicity where the big task is subdivided into manageable parts [18,39-41], with the assumption that the whole corresponds to the sum of the parts [39]. Nonetheless, narrowing down limits interpretation to a certain dimension, context, view, and configuration [42].

Silo thinking is singular in focus that is mostly associated with it and conveys the necessary definition of scope, context, dimension, and sphere that in turn influence reasoning and analysis $[18,43]$. The use of it pervades in science and engineering, particularly in investigating physical and chemical processes, but it has been used in the context of international development with the formulation of specific targets under specific development goals or with the translation of overarching development agenda into specific goals and objectives (e.g., Millennium Development Goals (MDGs) and Sustainable Development Goals (SDGs)) for clarity of action programs [39]. In development works, the reductionist approach must have been applied unintentionally, but clear directions have been brought about by it, although critics continue to question its relevance in CE implementation [44]. 
In the discourse of the $\mathrm{CE}$, the relevance of reductionism ranges from narrowly accepted to not at all $[39,43]$. With that kind of approach, too many blind sides create surprising outcomes, such as for example, in attaining the goal of reduced carbon emissions, industries have to slow down, if not invest in costly modern technologies with uncertain outcomes to profitability. For this reason, the CE is expected to slow down. Pieroni et al. [42] pointed out the relevance of the reductionist approach in the systemization of business models, in which the archetypes are threshed out with the said approach for proper contextualization, conceptualization, and structuring.

Reductionism is not entirely irrelevant in circular economy efforts. It has a place of its own, which contributes greatly to making holistic systems understandable and tractable for research and practice [42]. Holistic models and analysis need the specifics in elements and underlying relationships from reductionist models, whose combination constitutes the models consistent with the CE's systems thinking and analysis. On its own, reductionist models cripple the analytical frameworks of the $\mathrm{CE}$, and when unheeded, blind sides create surprisingly disappointing results [18]. In development programs, reductionist approaches create enormous contributions as to the clarity of direction, purpose, actions, and measures but not in analysis and prognosis of outcomes and impacts, particularly on a systems level. Underlying relationships and interactions can render the sum of all parts possibly unequal to their undivided whole, which the work of Skene [17] described with the patterns of interactions in natural systems that are cited as reasons for the impossibility of circular economy implementation at the grassroots. While debunking the relevance of reductionist approaches in CE discourse is quite correct, in building CE paradigms and frameworks, the reductionist approach is found essential. The said approach clarifies the abstraction that CE systems possess, which is important in understanding better CE implementation strategies. Holism is a relevant approach to understanding CE implementation, which borrows from reductionism the strategy of determining the elements to be put together to constitute a dynamic whole. The work of Jaspers et al. [45] demonstrates this, particularly with their research on metaorganism framework.

\section{Issues with Reductionism and Its Niche in Systems Thinking}

The downside of the reductionist approach is its obvious limitations brought about by the manner by which its analytical frameworks are developed-the emphasis of simplicity, tractability, clarity, and compartmentalization as opposed to complexity, intricacy, ambiguity, and inclusivity in systems approaches [41]. Its silo thinking and sufficient simplicity in analysis imply a dangerous curve ahead, which must be approached with extreme caution. Among others, Anastas [18], Korhonen et al. [2] and Skene [17] specifically warned the scientific and the global communities about this, arguing their point with some of the beneficial research results that turn out to have formidable impacts on socioeconomic welfare globally (doing the right things wrong-see Table 2 for more details), such that further developments of the said research results have to be rethought in view of the costs of their unintended outcomes unforeseen at the start. Historically, Thalidomide is one of the many famous examples to cite [18] for the demonstration of the downside of the reductionist approach. More of this is presented in Table 2, which is derived from the work of Anastas [18]. Those unintended consequences have been cited to be watched out for in the outputs of the reductionism/reductionist approach, as surprising challenges may confound the development interventions concerning technological, policy, and managerial endowments/complements [39], among others. The possibility of this is explained by the compartmentalized thinking that obscures underlying important links, interdependencies, and interrelationships that must have been part of the analytical and inferential paradigms [46]. Nonetheless, Korhonen et al. [2] have labels for said observations, which are associated with their propounded CE limits such as rebound effects, Jevon's paradox, and boomerang effects. 
Table 2. Demonstrating useful discoveries that possess deleterious impacts [18].

\begin{tabular}{|c|c|c|}
\hline \multicolumn{2}{|c|}{ Discoveries } & \multirow{2}{*}{$\begin{array}{l}\text { Impacts } \\
\text { Hazardous substances and byproducts killing } \\
\text { people every year }\end{array}$} \\
\hline 1. & Disinfecting agents in water & \\
\hline 2. & $\begin{array}{l}\text { Fertilizers for improved agricultural } \\
\text { productivity and food supply }\end{array}$ & $\begin{array}{l}\text { Water contamination, eutrophication and } \\
\text { biodiversity and ecosystem damage }\end{array}$ \\
\hline 3. & Replacement of bisphenol A & Toxicity concerns \\
\hline 4 . & $\begin{array}{l}\text { Discovery of life-saving drugs with } \\
\text { pharmaceuticals }\end{array}$ & Biologically active water contaminants \\
\hline 5. & Photovoltaics for solar energy & Toxic and depleting rare earth metals \\
\hline 6. & Biofuels & $\begin{array}{l}\text { Disruption in food and feed production, } \\
\text { competing land uses }\end{array}$ \\
\hline
\end{tabular}

Rebound effects, Jevon's paradox and boomerang effects have quite slight differences with each other. Obviously, they refer to the unintended outcomes accompanying or following the aims of research and development interventions. Undefined interlinkages have induced such outcomes, as set out in the works of Korhonen et al. [2] and Skene [17], which because of time and biophysical lags, manifest postintervention, usually at a rate unknown at the time they start showing up. This constitutes the blind sides of the reductionist approach and the reason for which surprising shortfalls of development efforts and initiatives happen in spite of careful planning and adequate funding/investments. Nonetheless, the compartmentalized tractability with the reductionist approach is the main reason for its being preferred repeatedly despite the various reminders of its inadequacies [44]. Tractability, especially in its analytical and inferential frameworks, produces the clues to the ways in which the potential repercussions and influences of any form of intervention are determined for comprehension and supposed proper action. Without this, it is convenient to debunk the relevance of the reductionist approach. However, Temesgen et al. [44] argued for the departure from this approach due to its hugely specialized nature to the point of being less helpful to the research community that draws important inferences and findings to guide future actions and decisions. They emphasize the exciting opportunity of developing new methodological perspectives to open up from such departure.

Systems thinking as a methodological perspective has been making waves quite recently as a result of having the surprising unintended outcomes generally allowing the persistence of varying unsustainable conditions. Anastas [18] made a point on such outcomes, which was a stern anecdotal warning of the infeasibility of CE implementation by Skene [17] and Korhonen et al. [2,16] particularly. Eskerod and Larsen [41] also commented that the reductionist approach was not dependable in projecting outcomes or results to come, in spite of the manageability of the approach in terms of cognitive capacity. However, the reductionist approach lends logic to the systems thinking process for its inclusivity. In the systems approach, the components' interrelationships and interdependencies are contributed to by the exacting nature of the reductionist approach, which provides coherence and logical configuration of these components for holistic evaluation [47]. Inoue [47] found the utility of the reductionist approach in idea generation pertinent to systems thinking with his research results exhibiting the functioning of reductionism through incomplete information and human cognitive ability in forming complex processes with a particular visualization procedure. Process designers or design practitioners benefit from such findings 
in their idea development [47], which by analogy the CE practitioners and stakeholders can learn from as well.

\section{Systems Thinking Challenges and Ways Forward}

Systems thinking is a radical departure from reductionism in which inclusivity tends to expand the scope of atomistic models / frameworks by drawing together relevant but fragmented ones to form a cohesive whole at the conceptual level. It adheres to the basic essence of a circular economy as systemic to begin with [48], which is reported in the review of seven works by Suárez-Eiroa et al. [49] for the CE's definitional issues. The use of causal loop diagrams (CLDs) complements the analytical frameworks for this aspect because of the fact that it illustrates the configuration of the system under study to exhibit the feedback loops that show the interactions of the system's "chains of cause-and-effect relationships" [50]. Bassi et al. [15] illustrates the most recent use of CLD relative to CE implementation, where the interaction of the critical variables shows the reinforcing (positive) and the balancing (negative) feedbacking in the territorybased CE implementation with specific stakeholders' assignments in the model for Europe (Figure 1). The CE yet lacks scientific traction [51]; but with growing advocacy among practitioners [49,51-53], it has drawn increasing attention recently from the scientific community to work on various aspects to establish the scientific foundation of the concept. Systems thinking is a critical baseline to set out the proper study of the concept as translated today into practice to resolve sustainability issues. Lu and Halog [54] emphasized this kind of mindset for the CE in the improvement and interconnectedness of analytical frameworks for food systems and diet sustainability issues. The systems frame of thinking provides an essential service in the discourse of $C E$ to support consequent empirical research, since that is what it is lacking at this point to establish the feasibility of CE as implemented in numerous sectors across the world [48,51]. Importantly, the overlaps of principles and goals as well as synergistic mechanisms are potential points of integration of atomistic models for a systems level of analysis in view of the advancement of the circular economy [55].

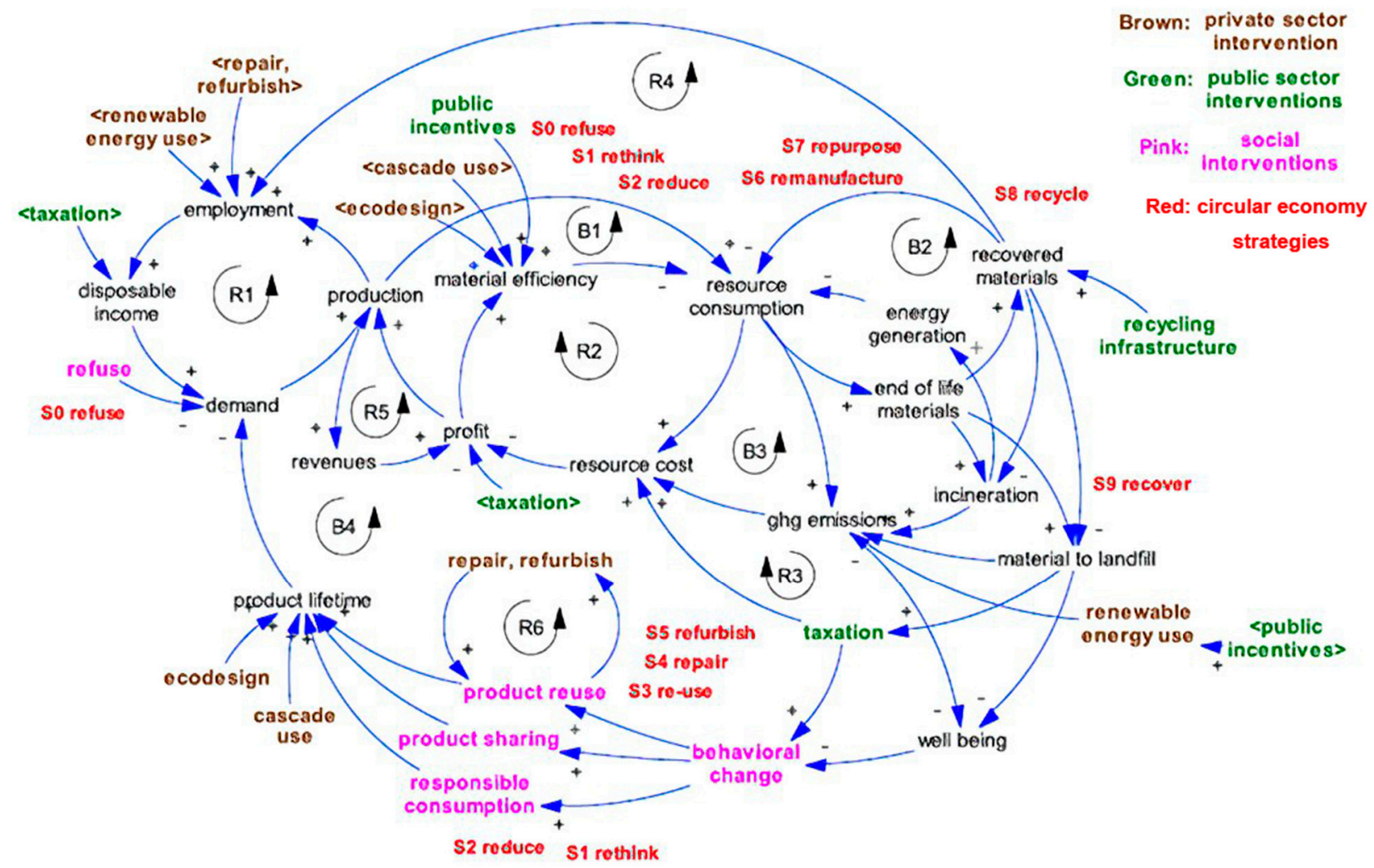

Figure 1. Causal loop diagram of general territory-based CE implementation [15]. 
Cabrera et al. [56] explained the evolution of systems thinking in four waves wherein time-stamped progression of the concept was laid out to note how it evolved over time based on heuristic concerns. The first wave was during the 1950s in direct response to the limitations of the traditional reductionist models, which have remained an issue seven decades after $[18,56]$. The early systems dynamic models remain an unpopular analytical choice up to this day, and despite evolving much over time, as well as the many structural, computational, and other developments for empirical quantitative analysis, they have still spread quite slowly. Somehow, this explains the reason why the CE yet lacks a display of holism and inclusivity in empirical research where relevant themes and trends are anticipated to blend in [57]. Systems thinking directs consequent analysis to be integrated or to appropriately be at systems level [56]. Progress of this is slow in methodological frameworks because the downsides of holistic system thinking and analysis, particularly towards the recent diversity and universality in methodological development, are difficult to address according to Cabrera et al. [56], as shown in Box 1. These downsides are highlighted in this work from the original work of Cabrera et al. [56] inasmuch as they remind of the observed fact about the difficulty of turfing or departing from domains and comfort zones of a field, pursuing the configuration challenges, and taking down walls of fragmentation for learning, besides the testing for the relevance and robustness of the derived system models. A great deal of accompanying complexity is hardly surmountable in the CE network yet.

Given the cross-section of current advocates of the CE, system approaches for empirical research still move slowly. Practitioners, specifically the nonacademic ones, have inadequate training to confront the technical challenges associated with the empirical research of the $C E$ on a systems level or with the use of quantitative system approaches. As observed, most of the adoption of systems thinking and approaches are yet at the conceptual level, such as that exhibited by Van Berkum et al. [58] and Lu and Halog [54] in food systems sustainability research, Cloke et al. [59] in social renewable energy systems, and Bassi et al. [15] in understanding further CE implementation in specific territories. However, the work of Muth et al. [60] on environmental and economic assessment of interventions on food loss and waste control in the US demonstrates the feasibility of applying system analysis to such a complex issue and the trans-disciplinarity required in accomplishing it, which underscores team effort and diversity to hurdle the technical challenges. Given this, for systems thinking to take off from a conceptual level of adoption to a level with explicit meaning in empirical research results, diversity of expertise is necessary besides the serious consideration of technical knowledge on undertaking systems analysis for empirical estimation. Muth et al. [60] defined the system in a supply chain context to comprehensively analyze the options to control food loss and waste in the US. In spite of the study being able to point out food loss and waste prevention as the soundest option, there is still a need to verify the findings due to challenges in available information and research tools [60]. Nonetheless, this work emphasizes the importance of furthering current developments on systems-related models and approaches, as this has been found highly relevant in the model characteristics suitable for CE implementation analysis. Further, in advocating for the CE through renewable energy sources, the systems approach is extremely helpful on the issue of food security with the use of food crops for energy (e.g., corn for ethanol vs. corn for food and feed). However, holonic systems towards a digitally-enabled transition to the $\mathrm{CE}$ is an exciting innovation to look forward to, as discussed in the works of Ávila-Gutiérrez et al. [61] and Martín-Gómez et al. [62]. Such systems are among the numerous opportunities to innovate with the existing CE systems to pursue closing the loops more effectively. However, the use of systems approaches in CE analysis has to progress to expedite the necessary learning processes among the researchers and the practitioners in the field. 
Box 1. The challenges of systems thinking and approaches [56].

1. The continuing proliferation of frameworks, approaches, and methodologies with each having its own spe-cialized lexicon, so that complexity of the field (beyond any single methodology) is hard for anyone to fully understand.

2. The concomitant partial fragmentation of the systems thinking research community, with divisions that reflect preferences of both methodologies (system dynamics, viable system modelling, soft systems method-ology, critical systems thinking, etc.) and application domains (engineering, operations research, public policy, environmental management, etc.).

3. The near impossibility of offering a two-minute introductory narrative to a newcomer to the systems thinking field that respects the variety of systems approaches.

4. The need for clarity and common purpose around unresolved questions and prospective research.

\section{Discussion and Conclusion}

The circular economy has been a promising concept towards sustainable development, which is extensively advocated by policymakers, business individuals, government units, and other practitioners across the world. With the increasing number of subscribing countries and institutions worldwide, it has gained much better traction over time with the demonstration of the concept's diversity of so-called implementable strategies and options to design waste out and to reduce pressure on natural resource stocks through a wide range of closed-loop strategies. Even on a conceptual level, the $\mathrm{CE}$ has been argued to be farfetched to impossible, as implementing circular strategies in the hope of designing waste out means undertaking similar processes of input and energy consumption and generating another kind of footprint to carry out the circular processes on a macro level (see Korhonen et al. [2,16] and Skene [17] for further explanation). Given natural laws, implementing the $\mathrm{CE}$ would mean attaining the sustainability targets at different kinds of costs. Anastas [18] mentioned some of these costs as a result of the discovery and implementation of beneficial interventions and knowledge products. In an attempt to circularize economies, several issues are noted to have caused impediments to CE implementation. This work has noted numerous inadequacies from the review of published CE initiatives since 2017, wherein addressing information, technology, and infrastructure needs is vital alongside with providing an enabling environment for the $\mathrm{CE}$ to take root through incentives, collaborative relationships, interest, and demand for new products and services, coherent directions, and meaningful standards, among others. These issues of CE implementation suggest the requisites that current societies and stakeholders have to work out to properly set up the enabling environment for the CE. With this, it has been shown that the CE will hardly be an implementable concept if those requisites are not responded to in time.

The persistent use of the reductionist approach perpetuates silo/compartmentalized thinking, which Anastas [18] demonstrated was a particular cause for shortfalls in the anticipation of unintended outcomes that again induce costs to the environment and society. This kind of approach is ruled out here as lacking relevance in the context of the CE where at the outset CE is already pronounced as systemic in nature. The use of the reductionist approach should have been expanded to be inclusive of relevant parameters to properly evaluate the overall results of a circular intervention. The system approach was already around by the time the CE was introduced since it was developed in the 1950s to address the inadequacies of the reductionist approach. The recent European Green Deal is interesting to be followed up on/followed through with based on the systems perspective. Such an ambitious sustainable development agenda across Europe is a bold move to reckon with for posterity where massive structural changes and tradeoffs are anticipated with its implementation. These changes and tradeoffs are the challenges of the European scientific community to prepare for consequences against its present industries running its macroeconomy. Having the $\mathrm{CE}$ as an important part of the Deal makes it highly ambitious, inasmuch as a macrolevel CE poses important unanswered questions, especially whether it is going to work and what transitional challenges will arise. The world will 
absolutely be watching for the unfolding of the CE under this Deal as an example for other countries to think about.

However, the application of the system approach to the CE is quite slow. Seven decades later, only a few studies have tried it in CE evaluation. Across the world, the CE still has very little empirical research with respect to conceptual research. The adoption of system analysis for the CE's implementation as demonstrated by Muth et al. [60] shows the rigors in undertaking it, which apparently requires transdisciplinarity, diversity of expertise, and team effort. System approaches are complex, which underlie interlinked relationships that reductionist models can help to form. However, these approaches are inclusive/comprehensive, which inform stakeholders through the preview of unintended outcomes beneficial in the evaluation of options (e.g., prevention vs. recycling in the study of Muth et al. [60] on food loss and waste via a supply chain framework). In addition, exciting frameworks for developing innovations at present are compatible with the $\mathrm{CE}$ as a system and timely integration of these may make CE more effective as a self-regenerating system. In view of the need to have holistic computable models via systems thinking, system analytical procedures (e.g., system dynamics, etc.) must further develop to advise the formulation of systems models relevant to the evaluation of $\mathrm{CE}$ initiatives.

This review mentions numerous challenges (see Box 1 ) on which the academic/scientific community can focus its attention. Inasmuch as those challenges comprise the void that needs to be explored at this point, these constitute the academic opportunities for the necessary attempts on the further development of the systems approaches for $\mathrm{CE}$ analysis and on making these approaches manageable for use among the stakeholders (particularly the researchers and the practitioners). Systems approaches have been unattractive for use because of the inherent complexities in using them. Further research on this aspect is suggested to define the complexity that addresses the major tradeoffs in the environment, the society, and the economy. Since the circular economy contributes towards sustainable development, the three pillars of SD must be represented in the systems model accordingly. Priority indicators of these pillars need to be considered. It is also interesting to look into the possibility of integrating the life-cycle based models in view of their various useful thresholds, critical impact indicators and temporal windows. In this situation, convergence of experts is necessary to deal with the challenges on the manageability of these complex systems models, with which the digital science experts can greatly help. Finally, based on relevance and generation of meaningful findings, this work emphasizes the importance of increasing the application of system models in the evaluation of CE issues and implementation to expedite the learning process about systems analytical tools among the various stakeholders for insightful basis in decision making regarding sustainability actions/programs.

Author Contributions: R.B. discussed the outline of this work with A.H. She collected and assessed the articles for the review and prepared the draft. A.H. conceptualized this work, provided guidance in the preparation of the draft, did the editing and the refinement of this work. Both authors have read and agreed to the published version of the manuscript.

Funding: This research received no external funding.

Institutional Review Board Statement: Not applicable.

Informed Consent Statement: Not applicable.

Data Availability Statement: Not applicable.

Conflicts of Interest: The authors have no conflict of interest with respect to this work.

\section{References}

1. Ritzén, S.; Sandström, G.Ö. Barriers to the Circular Economy—Integration of Perspectives and Domains. Proc. CIRP 2017, 64, 7-12. [CrossRef]

2. Korhonen, J.; Honkasalo, A.; Seppälä, J. Circular Economy: The Concept and Its Limitations. Ecol. Econ. 2017, 143, 37-46. [CrossRef] 
3. Geng, Y.; Fu, J.; Sarkis, J.; Xue, B. Towards a National Circular Economy Indicator System in China: An Evaluation and Critical Analysis. J. Clean. Prod. 2012, 23, 216-224. [CrossRef]

4. Iacovidou, E.; Millward-Hopkins, J.; Busch, J.; Purnell, P.; Velis, C.A.; Hahladakis, J.N.; Zwirner, O.; Brown, A. A Pathway to Circular Economy: Developing a Conceptual Framework for Complex Value Assessment of Resources Recovered from Waste. J. Clean. Prod. 2017, 168, 1279-1288. [CrossRef]

5. Mendoza, J.M.F.; Sharmina, M.; Gallego-Schmid, A.; Heyes, G.; Azapagic, A. Integrating Backcasting and Eco-design for the Circular Economy: The BECE Framework. J. Ind. Ecol. 2017, 21, 526-544. [CrossRef]

6. Zhou, Q.; Leng, G.; Su, J.; Ren, Y. Comparison of Urbanization and Climate Change Impacts on Urban Flood Volumes: Importance of Urban Planning and Drainage Adaptation. Sci. Total Environ. 2019, 658, 24-33. [CrossRef]

7. Kontgis, C.; Schneider, A.; Ozdogan, M.; Kucharik, C.; Duc, N.H.; Schatz, J. Climate Change Impacts on Rice Productivity in the Mekong River Delta. Appl. Geogr. 2019, 102, 71-83. [CrossRef]

8. Matsumoto, K.I. Climate Change Impacts on Socioeconomic Activities through Labor Productivity Changes Considering Interactions Between Socioeconomic and Climate Systems. J. Clean. Prod. 2019, 216, 528-541. [CrossRef]

9. Tabari, H. Climate Change Impact on Flood and Extreme Precipitation Increases with Water Availability. Sci. Rep. 2020, 10, 1-10.

10. Thompson, A. A Running List of Record-Breaking Natural Disasters in 2020. Available online: https:/ / www.scientificamerican. com/article/a-running-list-of-record-breaking-natural-disasters-in-2020/ (accessed on 13 March 2021).

11. Kalmykova, Y.; Sadagopan, M.; Rosado, L. Circular Economy-From Review of Theories and Practices to Development of Implementation Tools. Resour. Conserv. Recycl. 2017, 135, 190-201. [CrossRef]

12. McCarthy, A.; Dellink, R.; Bibas, R. The Macroeconomics of the Circular Economy Transition: A Critical Review of Modelling Approaches. Available online: https: / /www.oecd-ilibrary.org/docserver/af983f9a-en.pdf?expires=1619271150\&id=id\&accname= guest\&checksum=C8B06993CF162E2E06EC2CBB0A7D5AD6 (accessed on 13 March 2021).

13. Halog, A.; Balanay, R.; Anieke, S.; Yu, T.Y. Circular Economy across Australia: Taking Stock of Progress and Lessons. Circ. Econ. Sustain. 2021, 1-19. [CrossRef]

14. Qi, J.; Zhao, J.; Li, W.; Peng, X.; Wu, B.; Wang, H. Development of Circular Economy in China; Springer: Singapore, 2016; ISBN 978-981-10-2466-5.

15. Bassi, A.M.; Bianchi, M.; Guzzetti, M.; Pallaske, G.; Tapia, C. Improving the Understanding of Circular Economy Potential at Territorial Level Using Systems Thinking. Sustain. Prod. Consum. 2020, 27, 128-140. [CrossRef]

16. Korhonen, J.; Nuur, C.; Feldmann, A.; Birkie, S.E. Circular Economy as an Essentially Contested Concept. J. Clean. Prod. 2017, 175, 544-552. [CrossRef]

17. Skene, K.R. Circles, Spirals, Pyramids and Cubes: Why the Circular Economy Cannot Work. Sustain. Sci. 2017, 13, 479-492. [CrossRef]

18. Anastas, P.T. Beyond Reductionist Thinking in Chemistry for Sustainability. Trends Chem. 2019, 1, 145-148. [CrossRef]

19. Girard, L.F. The Circular Economy in Transforming a Died Heritage Site into a Living Ecosystem, to be Managed as a Complex Adaptive Organism. Aestimum 2020, 145-180. [CrossRef]

20. Potting, J.; Hanemaaijer, A.; Delahaye, R.; Ganzevles, J.; Hoekstra, R.; Lijzen, J. Circular Economy: What We Want to Know and Can Measure-System and Baseline Assessment for Monitoring the Progress of the Circular Economy in the Netherlands; PBL Netherlands Environmental Assessment Agency: Hague, The Netherlands, 2018; pp. 1-20.

21. Kirchherr, J.W.; van Santen, R. Research on the Circular Economy: A Critique of the Field. Resour. Conserv. Recycl. 2019, 151, 104480. [CrossRef]

22. Kirchherr, J.; Piscicelli, L.; Bour, R.; Kostense-Smit, E.; Muller, J.; Huibrechtse-Truijens, A.; Hekkert, M. Barriers to the Circular Economy: Evidence from the European Union (EU). Ecol. Econ. 2018, 150, 264-272. [CrossRef]

23. Schaubroeck, T. Circular Economy Practices May Not Always Lead to Lower Criticality or More Sustainability; Analysis and Guidance is Needed Per Case. Resour. Conserv. Recycl. 2020, 162, 104977. [CrossRef]

24. Agyemang, M.; Kusi-Sarpong, S.; Khan, S.A.; Mani, V.; Rehman, S.T.; Kusi-Sarpong, H. Drivers and Barriers to Circular Economy Implementation. Manag. Decis. 2018. [CrossRef]

25. Bressanelli, G.; Perona, M.; Saccani, N. Challenges in Supply Chain Redesign for the Circular Economy: A Literature Review and A Multiple Case Study. Int. J. Prod. Res. 2018, 57, 7395-7422. [CrossRef]

26. Govindan, K.; Hasanagic, M. A Systematic Review on Drivers, Barriers, and Practices towards Circular Economy: A Supply Chain Perspective. Int. J. Prod. Res. 2018, 56, 278-311. [CrossRef]

27. Hart, J.; Adams, K.; Giesekam, J.; Tingley, D.D.; Pomponi, F. Barriers and Drivers in a Circular Economy: The Case of the Built Environment. Proc. CIRP 2019, 80, 619-624. [CrossRef]

28. Kumar, V.; Sezersan, I.; Garza-Reyes, J.A.; Gonzalez, E.D.; Moh'd Anwer, A.S. Circular Economy in the Manufacturing Sector: Benefits, Opportunities and Barriers. Manag. Decis. 2019. [CrossRef]

29. Mak, T.M.; Xiong, X.; Tsang, D.C.; Iris, K.M.; Poon, C.S. Sustainable Food Waste Management Towards Circular Bioeconomy: Policy Review, Limitations and Opportunities. Bioresour. Technol. 2019, 297, 122497. [CrossRef]

30. Ormazabal, M.; Prieto-Sandoval, V.; Puga-Leal, R.; Jaca, C. Circular Economy in Spanish SMEs: Challenges and Opportunities. J. Clean. Prod. 2018, 185, 157-167. [CrossRef]

31. Carus, M.; Dammer, L. The Circular Bioeconomy-Concepts, Opportunities, and Limitations. Ind. Biotechnol. $2018,14,83-91$. [CrossRef] 
32. Bianchini, A.; Rossi, J.; Pellegrini, M. Overcoming the Main Barriers of Circular Economy Implementation Through a New Visualization Tool for Circular Business Models. Sustainability 2019, 11, 6614. [CrossRef]

33. Kerdlap, P.; Low, J.S.C.; Ramakrishna, S. Zero Waste Manufacturing: A Framework and Review of Technology, Research, and Implementation Barriers for Enabling a Circular Economy Transition in Singapore. Resour. Conserv. Recycl. 2019, 151, 104438. [CrossRef]

34. Reuter, M.A.; van Schaik, A.; Ballester, M. Limits of the circular economy: Fairphone modular design pushing the limits. World Metall. Erzmetall 2018, 71, 68-79.

35. Galvão, G.D.A.; de Nadae, J.; Clemente, D.H.; Chinen, G.; de Carvalho, M.M. Circular Economy: Overview of Barriers. Proc. CIRP 2018, 73, 79-85. [CrossRef]

36. Huang, Y.F.; Garrido, S.; Lin, T.J.; Cheng, C.S.; Lin, C.T. Exploring the Decisive Barriers to Achieve Circular Economy: Strategies for the Textile Innovation in Taiwan. Sustain. Prod. Consum. 2021. [CrossRef]

37. Cantú, A.; Aguiñaga, E.; Scheel, C. Learning from Failure and Success: The Challenges for Circular Economy Implementation in SMEs in an Emerging Economy. Sustainability 2021, 13, 1529. [CrossRef]

38. Zink, T.; Geyer, R. Circular Economy Rebound. J. Ind. Ecol. 2017, 21, 593-602. [CrossRef]

39. Zhang, Q.; Prouty, C.; Zimmerman, J.B.; Mihelcic, J.R. More than Target 6.3: A Systems Approach to Rethinking Sustainable Development Goals in a Resource-scarce World. Engineering 2016, 2, 481-489. [CrossRef]

40. Lanhoso, F.; Coelho, D.A. Emergence Fostered by Systemic Analysis-Seeding Innovation for Sustainable Development. Sustain. Dev. 2021, 1-12. [CrossRef]

41. Eskerod, P.; Larsen, T. Advancing Project Stakeholder Analysis by the Concept 'Shadows of the Context'. Int. J. Proj. Manag. 2017, 36, 161-169. [CrossRef]

42. Pieroni, M.P.; McAloone, T.C.; Pigosso, D.C. From Theory to Practice: Systematising and Testing Business Model Archetypes for Circular Economy. Resour. Conserv. Recycl. 2020, 162, 105029. [CrossRef]

43. Giampietro, M. Perception and Representation of the Resource Nexus at the Interface Between Society and the Natural Environment. Sustainability 2018, 10, 2545. [CrossRef]

44. Temesgen, A.; Storsletten, V.; Jakobsen, O. Circular Economy-Reducing Symptoms or Radical Change? Philos. Manag. 2019, 1-20. [CrossRef]

45. Jaspers, C.; Fraune, S.; Arnold, A.E.; Miller, D.J.; Bosch, T.C.; Voolstra, C.R. Resolving Structure and Function of Metaorganisms Through a Holistic Framework Combining Reductionist and Integrative Approaches. Zoology 2019, 133, 81-87. [CrossRef] [PubMed]

46. Desing, H.; Brunner, D.; Takacs, F.; Nahrath, S.; Frankenberger, K.; Hischier, R. A Circular Economy Within the Planetary Boundaries: Towards a Resource-based, Systemic Approach. Resour. Conserv. Recycl. 2020, 155, 104673. [CrossRef]

47. Inoue, S. Design Reductionism: Exploring the Potential Use of Reduced and Incomplete Information Acting as a Prompt for Designers' Imagination. Ph.D. Thesis, University of Northumbria, Newcastle, UK, December 2018.

48. Alhawari, O.; Awan, U.; Bhutta, M.K.S.; Ülkü, M.A. Insights from Circular Economy Literature: A Review of Extant Definitions and Unravelling Paths to Future Research. Sustainability 2021, 13, 859. [CrossRef]

49. Suárez-Eiroa, B.; Fernández, E.; Méndez-Martínez, G.; Soto-Oñate, D. Operational Principles of Circular Economy for Sustainable Development: Linking Theory and Practice. J. Clean. Prod. 2019, 214, 952-961. [CrossRef]

50. Clayton, A.M.H.; Radcliffe, N.J. Sustainability: A Systems Approach; Earthscan from Routledge; Routledge: New York, NY, USA, 1996; pp. 15-24.

51. Friant, M.C.; Vermeulen, W.J.; Salomone, R. A Typology of Circular Economy Discourses: Navigating the Diverse Visions of a Contested Paradigm. Resour. Conserv. Recycl. 2020, 161, 104917. [CrossRef]

52. Adams, K.T.; Osmani, M.; Thorpe, T.; Thornback, J. Circular Economy in Construction: Current Awareness, Challenges and Enablers. Waste Resour. Manag. 2017, 170, 15-24. [CrossRef]

53. Moktadir, M.A.; Rahman, T.; Rahman, M.H.; Ali, S.M.; Paul, S.K. Drivers to Sustainable Manufacturing Practices and Circular Economy: A Perspective of Leather Industries in Bangladesh. J. Clean. Prod. 2018, 174, 1366-1380. [CrossRef]

54. Lu, T.; Halog, A. Towards Better Life Cycle Assessment and Circular Economy: On Recent Studies on Interrelationships among Environmental Sustainability, Food Systems and Diet. Int. J. Sustain. Dev. World 2020, 27, 515-523. [CrossRef]

55. Schröder, P.; Bengtsson, M.; Cohen, M.; Dewick, P.; Hofstetter, J.; Sarkis, J. Degrowth Within-Aligning Circular Economy and Strong Sustainability Narratives. Resour. Conserv. Recycl. 2019, 146, 190-191. [CrossRef]

56. Cabrera, D.; Cabrera, L.; Midgley, G. (Eds.) The Four Waves of Systems Thinking. In Routledge Handbook of Systems Thinking, 1st ed.; Routledge: London, UK, 2021; pp. 1-44. [CrossRef]

57. Khitous, F.; Strozzi, F.; Urbinati, A.; Alberti, F. A Systematic Literature Network Analysis of Existing Themes and Emerging Research Trends in Circular Economy. Sustainability 2020, 12, 1633. [CrossRef]

58. Van Berkum, S.; Dengerink, J.; Ruben, R. The Food Systems Approach: Sustainable Solutions for a Sufficient Supply of Healthy Food; No. 2018-064; Wageningen Economic Research: Wageningen, The Netherlands, 2018; pp. 1-32.

59. Cloke, J.; Mohr, A.; Brown, E. Imagining Renewable Energy: Towards a Social Energy Systems Approach to Community Renewable Energy Projects in the Global South. Energy Res. Soc. Sci. 2017, 31, 263-272. [CrossRef] 
60. Muth, M.K.; Birney, C.; Cuéllar, A.; Finn, S.M.; Freeman, M.; Galloway, J.N.; Zoubek, S. A Systems Approach to Assessing Environmental and Economic Effects of Food Loss and Waste Interventions in the United States. Sci. Total Environ. 2019, 685, 1240-1254. [CrossRef] [PubMed]

61. Ávila-Gutiérrez, M.J.; Martín-Gómez, A.; Aguayo-González, F.; Lama-Ruiz, J.R. Eco-Holonic 4.0 Circular Business Model to Conceptualize Sustainable Value Chain towards Digital Transition. Sustainability 2020, 12, 1889. [CrossRef]

62. Martín-Gómez, A.; Ávila-Gutiérrez, M.J.; Aguayo-González, F. Holonic Reengineering to Foster Sustainable Cyber-Physical Systems Design in Cognitive Manufacturing. Appl. Sci. 2021, 11, 2941. [CrossRef] 